\title{
Molecular mechanism of CK19 involved in the regulation of postoperative recurrence of HBV-associated primary hepatocellular carcinoma in Guangxi
}

\author{
Hao Su${ }^{1,2 \#}$, Chuangye Han ${ }^{1,2 \#}$, Yongfei $\mathrm{He}^{1,2}$, Tianyi Liang ${ }^{1,2}$, Shutian Mo ${ }^{1,2}$, Chengkun Yang ${ }^{1,2}$, \\ Xiwen Liao ${ }^{1,2}$, Guangzhi Zhu ${ }^{1,2}$, Xinping Ye ${ }^{1,2}$, Tao Peng ${ }^{1,2}$ \\ ${ }^{1}$ Department of Hepatobiliary Surgery, The First Affiliated Hospital of Guangxi Medical University, Nanning, China; ${ }^{2}$ Guangxi Key Laboratory of \\ Enhanced Recovery after Surgery for Gastrointestinal Cancer, Nanning, China \\ Contributions: (I) Conception and design: T Peng; (II) Administrative support: T Peng; (III) Provision of study materials or patients: H Su, C Han; (IV) \\ Collection and assembly of data: Y He, T Liang, S Mo, G Zhu, X Ye; (V) Data analysis and interpretation: C Yang, X Liao; (VI) Manuscript writing: \\ All authors; (VII) Final approval of manuscript: All authors. \\ \#These authors contributed equally to this work. \\ Correspondence to: Tao Peng. Department of Hepatobiliary Surgery, The First Affiliated Hospital of Guangxi Medical University, Nanning, China. \\ Email: pengtaogmu@163.com.
}

Background: Cytokeratin 19 (CK19/KRT19) is a marker of biliary epithelial cells and hepatic progenitor cells, which can be expressed in some hepatocellular carcinoma (HCC). However, its role in the occurrence, development, and recurrence of hepatitis B virus (HBV)-associated HCC remains to be clarified. This study is to analyze the relationship between the expression of CK19 protein and clinicopathological factors, as well as the effect of positive CK19 expression on the prognosis of HCC patients.

Methods: Small interfering RNA (siRNA) transfection was used to silence CK19 in MHCC-97H and Hep-3B. Real time polymerase chain reaction (qPCR), immunohistochemistry (IHC), and flow cytometry were used to detect the effects of $C K 19$ silencing on cell function. High-throughput sequencing was used to explore the potential molecular mechanism of CK19 positive expression of HCC.

Results: In 24 patients with HCC, CK19 was only expressed in cancer tissues, regardless of primary or recurrent tumors, and the positive expression rate of recurrent tumors was higher than that of primary tumors. The HCC participants with positive primary CK19 expression had a shorter tumor-free survival time. Silencing of the CK19 gene in MHCC-97H and Hep-3B attenuated the migration and invasion ability of MHCC-97H, increased the G2 phase cell content of MHCC-97H and Hep-3B, and increased the proportion of apoptosis. High-throughput sequencing results suggested that changes in the function of the cell cycle regulating genes, drug, and carcinogenic metabolism might be the potential pathways of CK19 in regulating the biological behavior of $\mathrm{HCC}$.

Conclusions: Among HBV-related recurrent HCC, the positive rate of CK19 expression in recurrent HCC tumors was higher, and the tumor-free survival time of HCC patients with positive CK19 expression in primary HCC was shorter. After silencing of the CK19 gene, the migration and invasion ability of HCC cells were weakened, the content of G2-M cell cycle cells was increased, the invasion and migration of HCC cells were inhibited, and apoptosis was promoted. Changes in the function of the cell cycle regulating genes and the regulation of drug and carcinogenic metabolites-related pathways may be the pathways through which CK19 affects the biological behavior of HCC.

Keywords: Hepatocellular carcinoma (HCC); hepatitis B virus (HBV); cytokeratin 19 (CK19); prognosis; signaling pathway

Submitted Oct 28, 2021. Accepted for publication Dec 06, 2021.

doi: $10.21037 /$ atm-21-6020

View this article at: https://dx.doi.org/10.21037/atm-21-6020 


\section{Introduction}

Primary liver cancer (PLC) is a common malignant tumor worldwide and is one of the most common contributors to cancer mortality. Hepatocellular carcinoma (HCC) is the most common pathological type, accounting for more than $85-90 \%$ of PLC $(1,2)$. East Asia has a high incidence of $\mathrm{HCC}$ and chronic hepatitis $\mathrm{B}$ virus (HBV) infection and exposure to aflatoxin B1 (AFB1) are the main associated pathogenic factors (3). According to the epidemiological survey, Guangxi has a high incidence of PLC in China, which is significantly related to $\mathrm{HBV}$ infection, high AFB1 exposure, drinking water pollution, and other high-risk factors (4-7). Surgical resection is the main treatment of PLC, but postoperative recurrence is still the main issue leading to poor efficacy after simple surgical resection of liver tumor.

Cytokeratin 19 (CK19) is a marker of biliary epithelial cells and hepatic progenitor cells (HPC), can be expressed in some HCCs, and is a predictor of poor prognosis. The HCC subtypes expressing CK19 are significantly associated with tumor size, lower differentiation, microvascular invasion, metastasis, and recurrence, accompanied by poor prognosis (8-10). There are 2 possible sources of CK19 positive HCC: one is from dual-potential HPC that can differentiate into liver cells or bile duct cells; the other is the result of dedifferentiation of some HCC cells in the context of high heterogeneity within HCC. At present, it is still not clear why the biological behavior of HCC expressing CK19 has a higher degree of malignancy, and the specific molecular mechanism of CK19 positive expression affecting the poor prognosis of HCC has not been elucidated. Therefore, in-depth research is necessary, which has important practical significance for the prevention of postoperative recurrence of $C K 19$ positive HCC.

In this study, to investigate the influence of $C K 19$ positive expression on the prognosis of HCC, we retrospectively analyzed cases of recurrent $\mathrm{HCC}$ at the single center of The First Affiliated Hospital of Guangxi Medical University from 2002 to 2017. Through comparative analysis of HBVassociated primary HCC of the primary tumor and its relative expression of $C K 19$, we determined the differences between tumor recurrence and the relationship between the clinical, pathological features, and clinical prognosis. In addition, cell functions such as migration and invasion were detected after the CK19 gene was silenced by cell transfection technology, and the potential molecular mechanism of CK19 affecting malignant biological behavior of HCC cell lines was analyzed from the transcriptome level by whole transcriptome sequencing technology.

We present the following article in accordance with the MDAR reporting checklist (available at https://dx.doi. org/10.21037/atm-21-6020).

\section{Methods}

\section{Clinical data and sample collection}

A total of 24 patients with recurrent liver tumors after radical resection who underwent subsequent surgical resection or liver transplantation between 2002 to 2017 in The First Affiliated Hospital of Guangxi Medical University were recruited to the study. All patients met the following criteria: serological examination showed positive hepatitis B surface antigen (HBsAg); pathological specimens of recurrent tumors; pathological diagnosis of HCC; paraffin block specimens of HCC; and complete clinicopathological and prognostic data had been obtained. Laboratory results, surgical, pathological, tumor characteristics, and clinical outcomes were recorded. Follow-up information was obtained by telephone, outpatient records, and inpatient medical records. Death or recurrence (or extrahepatic metastasis) were the end events, and the follow-up period was up to December 2018. Disease-free survival (DFS) time was defined as the time HCC recurrence (or extrahepatic metastasis) after resection of liver tumor. The study was conducted in accordance with the Declaration of Helsinki (as revised in 2013), and approved by the Ethics Committee of the First Affiliated Hospital of Guangxi Medical University (No. 2015-KY-072). The patients were fully informed about the nature of this experiment and their informed consent was provided.

\section{Cell culture}

We obtained HCC cell lines (Hep G2, SK-Hep-1, SNU449, SNU-182, SMMC-7721, Hep-3B, MHCC97-H, MHCC97-L, Huh7, and HCCLM3) from The Cell Resource Center of Shanghai Institutes of Biological Sciences (SIBS), Chinese Academy of Sciences (Shanghai, China). In T25 cell culture vials, cells were cultured with $10 \%$ fetal bovine serum (FBS; Gibco-life Technologies, Carlsbad, CA, USA) and 1\% penicillin/streptomycin (Gibco-life Technologies, Carlsbad, CA, USA) in Roswell Park Memorial Institute (RPMI) 1640 or Dulbecco's modified Eagle medium (DMEM). 


\section{Reagents and antibodies}

The following reagents were used in this study: Matrigel and Transwell cell culture inserts (Corning, Corning, NY, USA); TRIzol reagent (Invitrogen, Carlsbad, CA, USA); human peripheral blood whole genome DNA extraction kit (Promega, Madison, WI, USA); first strand cDNA synthesis kit (Thermo Fisher Scientific, Waltham, MA, USA); RevertAid first strand cDNA (Fermentas, Waltham, MA, USA); cell cycle detection Kit (BestBio, Shanghai, China); double staining cell apoptosis detection kit (BestBio); siRNA kit (Ruibo Biotechnology Co., Ltd., Guangzhou, China); radioimmunoprecipitation assay (RIPA) tissue/cell rapid lysis fluid; phenylmethylsulfonyl fluoride (PMSF); and protease inhibitor mixture and bicinchoninic acid (BCA) protein detection kit (Beyotime, Shanghai, China). The following antibodies were used in this study: anticytokeratin 19 (Abcam, Cambridge, UK), goat anti-rabbit secondary antibody (E031120-2, EarthOx Life Sciences, Millbrae, CA, USA), horseradish peroxidase (HRP) labeled goat anti-rabbit IgG (Servicebio, Hubei, China).

\section{Transwell invasion and migration assay}

Matrigel was diluted in pre-cooled serum-free medium at a ratio of 1:8. In the invasion experiment, Matrigel was coated with $50 \mu \mathrm{L}$ diluted Matrigel in the Transwell chamber, and then gelated in an incubator at $37^{\circ} \mathrm{C}$ for $1 \mathrm{~h}$. No treatment was required to transfer the experimental chamber. Then, $10 \times 10^{4}$ cells were incubated in $100 \mu \mathrm{L}$ medium containing $1 \%$ serum in the upper chamber and $800 \mu \mathrm{L}$ medium containing $30 \%$ serum in the lower chamber in a $37{ }^{\circ} \mathrm{C}$ incubator with $5 \% \mathrm{CO}_{2}$. After $48 \mathrm{~h}$ of culture, the upper chamber was cleaned with phosphate-buffered saline (PBS) to remove the upper chamber cells. The cells were fixed at the lower side of the chamber with $4 \%$ paraformaldehyde and stained with crystal violet $(0.1 \%)$ at room temperature for $30 \mathrm{~min}$. After washing and drying, stained cells were those that has invaded the lower compartment. We randomly selected 5 fields under an inverted microscope to calculate relative invasions.

\section{Wound bealing assay}

The cells were digested and $1 \mathrm{~mL}$ medium containing $2 \times 10^{5}$ cells and then added to each well of the 12 -well plate. The cells were cultured in an incubator at $37{ }^{\circ} \mathrm{C}$ with $5 \%$ $\mathrm{CO}_{2}$ for $24 \mathrm{~h}$. After cell convergence had reached $100 \%$, a $100 \mu \mathrm{L}$ pipette tip was used to form a scratch on the cell in the center of each well. Images were taken at 0 and $24 \mathrm{~h}$ ( $\geq 5$ fields/h), and images of each group were calculated by Image J software (https://imagej.nih.gov/ij/) to obtain the size of scratch blank area at different time points. Migration area was calculated by the following formula: migration area $(24 \mathrm{~h})=$ blank area $(0 \mathrm{~h})$ - blank area $(24 \mathrm{~h})$.

\section{Cell cycle analysis}

Cells were collected and immobilized overnight with a final concentration of $70 \%$ ethanol. Next, the cells were washed with PBS to remove the ethanol. Finally, the cells were stained according to the cell cycle detection kit and kept away from light for $30 \mathrm{~min}$ at room temperature. Flow cytometry was used to analyze cell cycle distribution.

\section{Apoptosis analysis}

Cells were digested by trypsin without ethylenediamine tetraacetic acid (EDTA) and collected. Annexin V-FITC and propidium iodide (PI) staining were performed according to the apoptosis detection kit. Apoptosis rate was assessed by flow cytometry.

\section{Small interfering RNA (siRNA) cells were transfected}

Transfection was performed using Ruibo siRNA reagent according to the manufacturer's instructions. We inoculated $2 \times 10^{5}$ cells into a 24 -well plate culture well containing adequate complete medium to achieve $50 \%$ cell density during transfection. Diluted siRNA mixture was added according to the instructions, and the culture plate was placed in a $\mathrm{CO}_{2}$ incubator at $37^{\circ} \mathrm{C}$ for $48 \mathrm{~h}$. The siRNA silencing effect could be detected $48 \mathrm{~h}$ after transfection. Target gene messenger RNA (mRNA) expression was detected by reverse transcription polymerase chain reaction (RT-PCR) $48 \mathrm{~h}$ after siRNA transfection, and protein expression was detected by western blot $72 \mathrm{~h}$ after transfection.

\section{RT-PCR}

Total RNA was extracted with TRIzol reagent, and complementary DNA (cDNA) was prepared by reverse transcription according to the reverse transcription reagent of first strand cDNA synthesis kit. Target genes were amplified by PCR using the following specific primers: glyceraldehyde 3-phosphate dehydrogenase (GAPDH), 
upstream primers 5'-CaaATTCCATGGCACCGTCA-3', downstream primers 5'-GactCCACGACGTACTCAGC-3'. CK19, upstream primer 5'-CGACTACAGCC ACTACTACACGA-3', downstream primer 5'-ACAATCCTGGagTTCTCAATGG-3. An ABI Q6 fluorescence quantitative PCR (Applied Biosystems, Waltham, MA, USA) was used to detect gene expression levels, and $2^{-\Delta \Delta \mathrm{Ct}}$ was used to calculate the results.

\section{Western blot analysis}

High-potency RIPA tissue/cell rapid lysate, PMSF, and protease inhibitor mixtures were mixed in a 100:1:1 ratio to extract proteins from cells. The BCA protein detection kit was used to detect protein concentration. The protein samples $(30 \mu \mathrm{g})$ were electrophoresed with sodium dodecyl sulfate-polyacrylamide gel electrophoresis (SDS-PAGE), and the protein signals were transferred to the polyvinylidene fluoride (PVDF) membrane by electroblotting. After the membrane was closed, it was soaked overnight in the primary antibody at $4^{\circ} \mathrm{C}$, and then incubated in a secondary antibody at room temperature for $1 \mathrm{~h}$ on a shaker. The film was placed in gel imaging software for scanning analysis.

\section{Immunobistochemistry (IHC)}

IHC analysis was performed to detect the expression of CK19 in tissues and cells. The paraffin section was dewaxed and the antigen was repaired, the endogenous peroxidase was blocked with $3 \%$ bovine serum albumin (BSA), then the anti-CK19 antibody was incubated overnight at $4{ }^{\circ} \mathrm{C}$. On the second day, the sections were incubated with goat anti-rabbit (HRP), stained with 3,3'-diaminobenzidine (DAB) chromogen, and restained with hematoxylin. The sections were observed and analyzed using an optical microscope. The IHC staining results of CK19 protein were independently reviewed and scored by 2 pathologists. Positive cells were defined as CK19 cells with brownishyellow staining particles in the cytoplasm. For scoring, positive $C K 19$ expression was defined as $\geq 5 \%$ of tumor cells, and negative CK19 expression was defined as less than $5 \%$ of tumor cells.

\section{Detection of codon 249 mutation of TP53 gene}

We extracted DNA from HCC tissues using DNA extraction kits, and the human TP53 gene sequence was searched on the National Center for Biotechnology Information (NCBI) database of the United States. Primers were designed for the 249 codons of the TP53 gene by Premier 5.0 software (Sangon, Shanghai, China), and the feasibility of primers was evaluated by OLIGO 7.0 software (https://www.oligo. net/) $(11,12)$. The primers for mutation detection of the 249 codons of TP53 gene included an upstream primer: 5'-CTTGCCACAGGTCTCCCCAA-3, and downstream primer: 5'-AGGGGTCAGAGGCaAGAGAGA-3. The extracted DNA was amplified according to Hostmaster hot Start kit and ABI9700 PCR instrument (Applied Biosystems), and the amplified product was detected by the Sanger sequencing method to detect the mutation of codon 249 of the TP53 gene in HCC tissues.

\section{Transcriptome sequencing}

We selected the Hep-3B cells with the best growth status for the siRNA transfection experiment. After $48 \mathrm{~h}$, total RNA was extracted by the TRIzol method to detect the purity and concentration of RNA. Qualified RNA samples were used for subsequent library construction and sequenced using the Illumina HiSeq platform (Illumina, San Diego, CA, USA). We used EdgeR software (https:// bioconductor.org/packages/release/bioc/html/edgeR. $\mathrm{html}$ ) to analyze the differences in gene expression between groups, and the Gene Ontology (GO) database was used to analyze the GO biological functions of differential genes and establish the GO biological process distribution map. The Kyoto Encyclopedia of Genes and Genomes (KEGG) database was used to enrich, annotate, and analyze signal pathways of differential genes.

\section{Statistical analysis}

The statistical software SPSS 22.0 (IBM Corp. Armonk, NY, USA) was used to analyze the data, and the measurement data were expressed as mean \pm standard deviation $\left(\bar{x}_{ \pm}\right)$. One-way analysis of variance (ANOVA) was used for comparison between groups, and $\mathrm{P}<0.05$ was considered statistically significant.

\section{Results}

\section{Baseline characteristics of the study population}

The serum HBsAg of all 24 HCC patients in this study was positive, and the pathological diagnosis of HCC was 
Table 1 Summary of basic clinical information of 24 HCC patients

\begin{tabular}{|c|c|}
\hline Variable & Number (\%) \\
\hline \multicolumn{2}{|l|}{ Gender } \\
\hline Male & $21(87.5)$ \\
\hline Female & $3(12.5)$ \\
\hline Age (years) & 45 \\
\hline \multicolumn{2}{|l|}{ Ethnicity } \\
\hline Han & $12(50.0)$ \\
\hline Minority & $12(50.0)$ \\
\hline \multicolumn{2}{|l|}{ Smoking } \\
\hline Yes & $6(25.0)$ \\
\hline No & $18(75.0)$ \\
\hline \multicolumn{2}{|l|}{ Drinking } \\
\hline Yes & 8 (33.3) \\
\hline No & $16(66.7)$ \\
\hline \multicolumn{2}{|l|}{ BMI } \\
\hline$\leq 25$ & $19(79.2)$ \\
\hline$>25$ & $5(20.8)$ \\
\hline \multicolumn{2}{|l|}{ Liver fluke } \\
\hline Yes & $2(8.3)$ \\
\hline No & $22(91.7)$ \\
\hline \multicolumn{2}{|c|}{ Antiviral therapies } \\
\hline Yes & $10(41.7)$ \\
\hline No & 8 (33.3) \\
\hline NA & $6(25.0)$ \\
\hline \multicolumn{2}{|l|}{ Diabetes } \\
\hline Yes & 0 \\
\hline No & $24(100.0)$ \\
\hline
\end{tabular}

HCC, hepatocellular carcinoma; BMI, body mass index.

confirmed by surgical resection of liver tumor specimens. The median age was 45 years (23-66 years), and there were 3 females (12.5\%) and 21 males $(87.5 \%)$. There were 12 participants of Han nationality (50\%) and 12 participants of minority nationality $(50 \%)$. A total of 6 participants $(25 \%)$ were smokers; 8 (33.33\%) had a drinking history; and 2 $(8.33 \%)$ were infected with fluke hepatica. There were 10 participants $(41.67 \%)$ who had received antiviral therapy (Table 1, Table S1).

\section{CK19 IHC and mutation profile of codon 249 of TP53 gene}

In this study, among the 24 HCC patients, CK19 expression was positive in 2 cases $(8.33 \%)$ and negative in 22 cases $(91.67 \%)$ of the primary cancer tissues surgically removed for the first time; however, CK19 expression was positive in 11 cases $(45.83 \%)$ and negative in 13 cases $(54.17 \%)$ of the recurrent cancer tissues surgically removed for the second time (Table 2). The CK19 protein was expressed in all HCC cancer tissues but was not detected in para-cancer tissues. Mutation of the 249th codon of the P53 gene was detected by the Sanger sequencing method (Figure S1) in 24 cases, and the result indicated mutation in 8 cases $(33.3 \%)$.

\section{Expression, clinical factors, and prognosis of CK19 in HCC tissues}

The expression of $C K 19$ protein was compared with the degree of tumor differentiation (high, medium, and low), preoperative alpha fetoprotein (AFP) level (>400 ng/mL, $\leq 400 \mathrm{ng} / \mathrm{mL}$ ), preoperative HBV-DNA level (positive and negative), whether radical surgical resection was performed, preoperative liver function Child-Pugh grading, and whether cirrhosis was associated with 24 HCC patients after 2 surgeries, mutation of TP53 gene 249 codons in cancer tissue, invasion of large vessels, tumor size $(>5 \mathrm{~cm}, \leq 5 \mathrm{~cm})$, number of tumors (single, multiple), and Barcelona Clinic Liver Cancer (BCLC) stage of liver cancer were analyzed. The results showed that there was no significant correlation between the expression of $C K 19$ in cancer tissues of primary and recurrent tumors and these clinical factors (Table 3). In addition, the comparison of clinical and pathological factors of the primary tumor and the recurrent tumor in HCC patients showed that the differentiation degree of the recurrent tumor was significantly different from that of the primary tumor $\left(\chi^{2}=4.128, \mathrm{P}=0.047\right)$, and the positive rate of CK19 expression in the recurrent tumor was significantly higher than that of the primary tumor $\left(\chi^{2}=8.545, \mathrm{P}=0.003\right)$ (Table 4). The tumor-free survival time of 24 HCC patients was correlated with the expression of CK19 in tumor tissues ( $\log$-rank $\mathrm{P}=0.05)$, and the tumor-free survival time of recurrent tumors was significantly correlated with the BCLC stage $(\log$-rank $\mathrm{P}<0.001)$. However, there was no significant correlation between the expression of CK19 in cancer tissues (log-rank $\mathrm{P}=0.56)$. In addition, there was no significant difference in tumor-free survival time between primary and recurrent tumors $(\mathrm{P}=0.130)$ (Figures $1-3)$. 
Table 2 CK19 immunohistochemical score of 24 samples

\begin{tabular}{|c|c|c|c|c|c|c|c|c|}
\hline \multirow{2}{*}{ Sample ID } & \multicolumn{4}{|c|}{ Primary tumor CK19 } & \multicolumn{4}{|c|}{ Recurrent tumor CK19 } \\
\hline & $\mathrm{ca} \%$ & $\mathrm{p} \%$ & $\mathrm{ca}$ & $\mathrm{p}$ & $\mathrm{ca} \%$ & $\mathrm{p} \%$ & $\mathrm{ca}$ & $p$ \\
\hline $\mathrm{P} 1$ & 0 & 0 & $(-)$ & $(-)$ & 20 & 0 & $(+)$ & $(-)$ \\
\hline P2 & 0 & 0 & $(-)$ & $(-)$ & 30 & 0 & $(++)$ & $(-)$ \\
\hline P3 & 0 & 0 & $(-)$ & $(-)$ & 0 & 0 & $(-)$ & $(-)$ \\
\hline P4 & 0 & 0 & $(-)$ & $(-)$ & 40 & 0 & $(+)$ & $(-)$ \\
\hline P5 & 0 & 0 & $(-)$ & $(-)$ & 50 & 0 & $(+)$ & $(-)$ \\
\hline P6 & 0 & 0 & $(-)$ & $(-)$ & 0 & 0 & $(-)$ & $(-)$ \\
\hline P7 & 30 & 0 & $(+++)$ & $(-)$ & 0 & 0 & $(-)$ & $(-)$ \\
\hline P8 & 0 & 0 & $(-)$ & $(-)$ & 0 & 0 & $(-)$ & $(-)$ \\
\hline P9 & 0 & 0 & $(-)$ & $(-)$ & 50 & 0 & $(+)$ & $(-)$ \\
\hline P10 & 0 & 0 & $(-)$ & $(-)$ & 20 & 0 & $(++)$ & $(-)$ \\
\hline P11 & 0 & 0 & $(-)$ & $(-)$ & 70 & 0 & $(+)$ & $(-)$ \\
\hline P12 & 0 & 0 & $(-)$ & $(-)$ & 0 & 0 & $(-)$ & $(-)$ \\
\hline P13 & 0 & 0 & $(-)$ & $(-)$ & 90 & 0 & $(+++)$ & $(-)$ \\
\hline P14 & 40 & 0 & $(++)$ & $(-)$ & 90 & 0 & $(++)$ & $(-)$ \\
\hline P15 & 0 & 0 & $(-)$ & $(-)$ & 80 & 0 & $(+)$ & $(-)$ \\
\hline P16 & 0 & 0 & $(-)$ & $(-)$ & 0 & 0 & $(-)$ & $(-)$ \\
\hline P17 & 0 & 0 & $(-)$ & $(-)$ & 50 & 0 & $(++)$ & $(-)$ \\
\hline P18 & 0 & 0 & $(-)$ & $(-)$ & 0 & 0 & $(-)$ & $(-)$ \\
\hline P19 & 0 & 0 & $(-)$ & $(-)$ & 0 & 0 & $(-)$ & $(-)$ \\
\hline P20 & 0 & 0 & $(-)$ & $(-)$ & 0 & 0 & $(-)$ & $(-)$ \\
\hline P21 & 0 & 0 & $(-)$ & $(-)$ & 0 & 0 & $(-)$ & $(-)$ \\
\hline P22 & 0 & 0 & $(-)$ & $(-)$ & 0 & 0 & $(-)$ & $(-)$ \\
\hline P23 & 0 & 0 & $(-)$ & $(-)$ & 0 & 0 & $(-)$ & $(-)$ \\
\hline P24 & 0 & 0 & $(-)$ & $(-)$ & 0 & 0 & $(-)$ & $(-)$ \\
\hline
\end{tabular}

CK19, cytokeratin 19; -, negative; +, positive.

\section{The expression level of CK19 gene in various hepatoma cell lines}

Combined with fluorescent quantitative PCR results, western blot results, and IHC results of CK19 gene in various hepatoma cell lines, it could be seen that the expression level of CK19 gene in MHCC-97H and Hep$3 \mathrm{~B}$ cells has the best relative effect. Therefore, MHCC97H and Hep-3B liver cancer cell lines were selected for subsequent silencing experiments (Figures S2,S3).
Effect of siRNA targeted silencing of CK19 gene on migration and invasion ability of MHCC-97H and Hep-3B

The effect of silencing CK19 on HCC cell lines was examined by scratch test. The results showed that after $24 \mathrm{~h}$ of scratches, the horizontal migration ability of cells in the MHCC-97H group was lower than that in the other 2 groups, and the migration area of cells in the CK19 silenced group was smaller than that in the other 2 groups, 
Table 3 Univariate correlation analysis between the expression of CK19 and clinicopathological factors in primary and recurrent HCC

\begin{tabular}{|c|c|c|c|c|c|c|c|c|}
\hline Variable & \multicolumn{4}{|c|}{ Primary tumor } & \multicolumn{4}{|c|}{ Recurrent tumor } \\
\hline Tumor differentiation & & & 1.989 & 1 & & & & NA \\
\hline Well & 0 & 1 & & & 0 & 0 & & \\
\hline Moderate & 2 & 15 & & & 9 & 12 & & \\
\hline NA & & & & & & & & \\
\hline $\operatorname{AFP}(\mathrm{ng} / \mathrm{mL})$ & & & & 1 & & & & 0.617 \\
\hline$>400$ & 0 & 7 & & & 2 & 3 & & \\
\hline$\leq 400$ & 2 & 14 & & & 9 & 6 & & \\
\hline Yes & 2 & 8 & & & 4 & 6 & & \\
\hline No & 0 & 8 & & & 4 & 4 & & \\
\hline NA & & & & & & & & \\
\hline Radical resection & & & & 1 & & & & 1 \\
\hline Yes & 1 & 12 & & & 7 & 9 & & \\
\hline No & 1 & 8 & & & 2 & 2 & & \\
\hline NA & & & & & & & & \\
\hline Child-Pugh & & & & 1 & & & & NA \\
\hline TP53 mutation & & & & 1 & & & & 0.679 \\
\hline Yes & 1 & 7 & & & 3 & 5 & & \\
\hline No & 1 & 15 & & & 8 & 8 & & \\
\hline Vascular invasion & & & & 1 & & & & 1 \\
\hline Yes & 0 & 2 & & & 2 & 2 & & \\
\hline No & 2 & 20 & & & 9 & 11 & & \\
\hline Tumor size $(\mathrm{cm})$ & & & & 0.199 & & & & 1 \\
\hline$>5$ & 0 & 16 & & & 5 & 6 & & \\
\hline$\leq 5$ & 2 & 6 & & & 6 & 7 & & \\
\hline Tumor number & & & & 0.076 & & & & 1 \\
\hline Single & 0 & 17 & & & 7 & 11 & & \\
\hline
\end{tabular}

Table 3 (continued) 
Table 3 (continued)

\begin{tabular}{|c|c|c|c|c|c|c|c|c|}
\hline Variable & \multicolumn{4}{|c|}{ Primary tumor } & \multicolumn{4}{|c|}{ Recurrent tumor } \\
\hline Multiple & 2 & 5 & & & 3 & 3 & & \\
\hline BCLC stage & & & 1.548 & 0.622 & & & 0.453 & 1 \\
\hline$A$ & 1 & 14 & & & 8 & 9 & & \\
\hline $\mathrm{C}$ & 0 & 4 & & & 1 & 2 & & \\
\hline
\end{tabular}

CK19, cytokeratin 19; HCC, hepatocellular carcinoma; AFP, $\alpha$-fetoprotein; BCLC, Barcelona Clinic Liver Cancer.

Table 4 Clinicopathological parameters of primary and recurrent tumors in 24 HCC patients

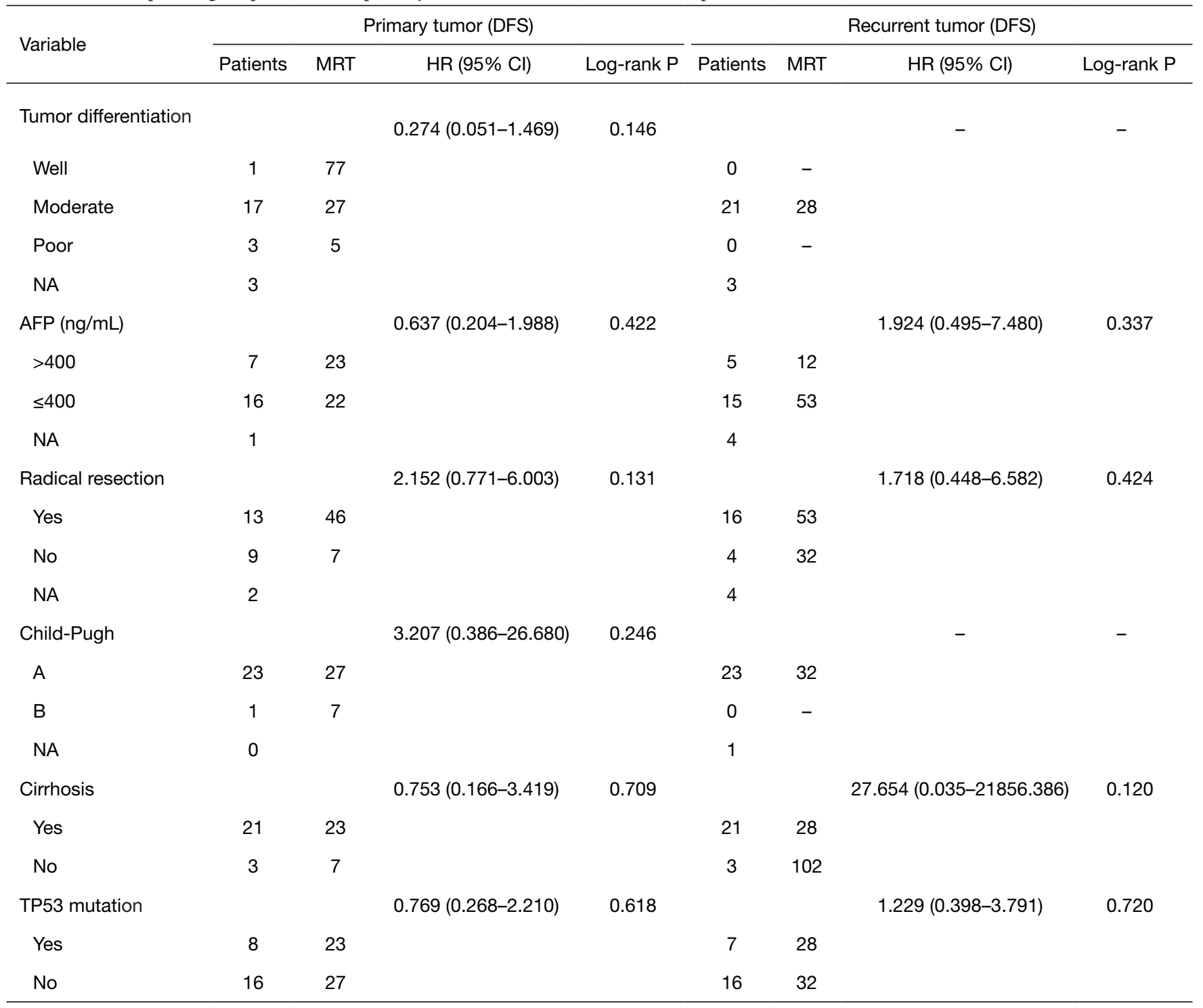

Table 4 (continued) 
Table 4 (continued)

\begin{tabular}{|c|c|c|c|c|c|c|c|c|}
\hline Variable & \multicolumn{4}{|c|}{ Primary tumor (DFS) } & \multicolumn{4}{|c|}{ Recurrent tumor (DFS) } \\
\hline NA & 0 & & & & 1 & & & \\
\hline Vascular invasion & & & $0.531(0.069-4.087)$ & 0.526 & & & $1.516(0.411-5.599)$ & 0.529 \\
\hline Yes & 2 & 29 & & & 4 & 53 & & \\
\hline Tumor size (cm) & & & $1.094(0.392-3.056)$ & 0.860 & & & $1.478(0.486-4.498)$ & 0.489 \\
\hline$>5$ & 16 & 23 & & & 11 & 26 & & \\
\hline$\leq 5$ & 8 & 27 & & & 13 & 53 & & \\
\hline Tumor number & & & $0.798(0.257-2.473)$ & 0.689 & & & $1.615(0.470-5.547)$ & 0.443 \\
\hline BCLC stage & & & $1.044(0.513-2.125)$ & 0.282 & & & $5.053(1.850-13.803)$ & $<0.001$ \\
\hline$A$ & 15 & 27 & & & 17 & 53 & & \\
\hline B & 5 & 23 & & & 4 & 15 & & \\
\hline $\mathrm{C}$ & 4 & 7 & & & 3 & 3 & & \\
\hline CK19 & & & $4.215(0.868-20.463)$ & 0.05 & & & $0.718(0.235-2.198)$ & 0.56 \\
\hline Negative & 22 & 27 & & & 13 & 26 & & \\
\hline Positive & 2 & 3 & & & 11 & 32 & & \\
\hline
\end{tabular}

HCC, hepatocellular carcinoma; AFP, $\alpha$-fetoprotein; BCLC, Barcelona Clinic Liver Cancer; CK19, cytokeratin 19; DFS, disease-free survival; MRT, median recurrence time; NA, not available; HR, hazard ratio; $\mathrm{Cl}$, confidence interval.

but the difference in migration area was not statistically significant. Similar results were observed in the Hep$3 \mathrm{~B}$ cell line. In terms of invasion ability, that of MHCC$97 \mathrm{H}$ cells was significantly decreased after silencing of CK19, but the invasion ability of Hep-3B cell line was not significantly decreased (Figure 4).

\section{siRNA targeted silencing of CK19 gene on MHCC-97H and Hep-3B cell cycle and apoptosis}

The results of cell cycle detection showed that there was no statistically significant difference in the percentage of cell content in the G2 phase between the CK19 silent group and the other 2 groups in the MHCC-97H cell line $(\mathrm{P}>0.05)$, but there was a significant increase in the percentage of cell content in G2 phase between the CK19 silent group and the other 2 groups in Hep-3B cell line $(\mathrm{P}<0.05)$. Apoptosis analysis showed that the percentage of apoptosis in the
MHCC-97H cell line was higher in the CK19 silenced group than in the other 2 groups, and the difference was statistically significant $(\mathrm{P}<0.05)$. In the Hep-3B cell line, the percentage of apoptosis in the CK19 silenced group was higher than that in the $\mathrm{NC}$ group. The difference was statistically significant $(\mathrm{P}<0.05)$ (Figure 5).

\section{Full transcriptome analysis of Hep-3B cells after siRNA targeted silencing of CK19}

Total transcriptome analysis of CK19 positive Hep-3B cells was performed using high-throughput sequencing technology. The results showed that 1,099 long non-coding RNAs (lncRNAs; 601 up-regulated, 498 down-regulated), 10 circles (4 up-regulated, 6 down-regulated), 281 micro RNAs (miRNAs; 178 up-regulated, 103 down-regulated), and 779 mRNAs (393 up-regulated, 386 down-regulated) were closely related to the expression of CK19 by HCC. 

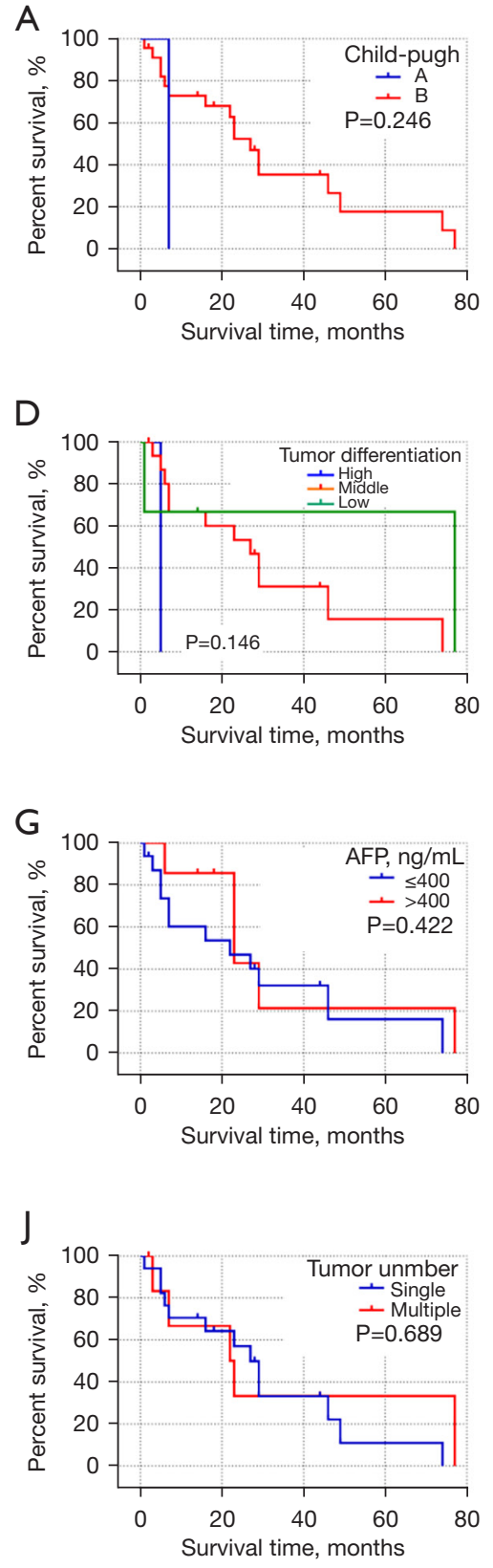
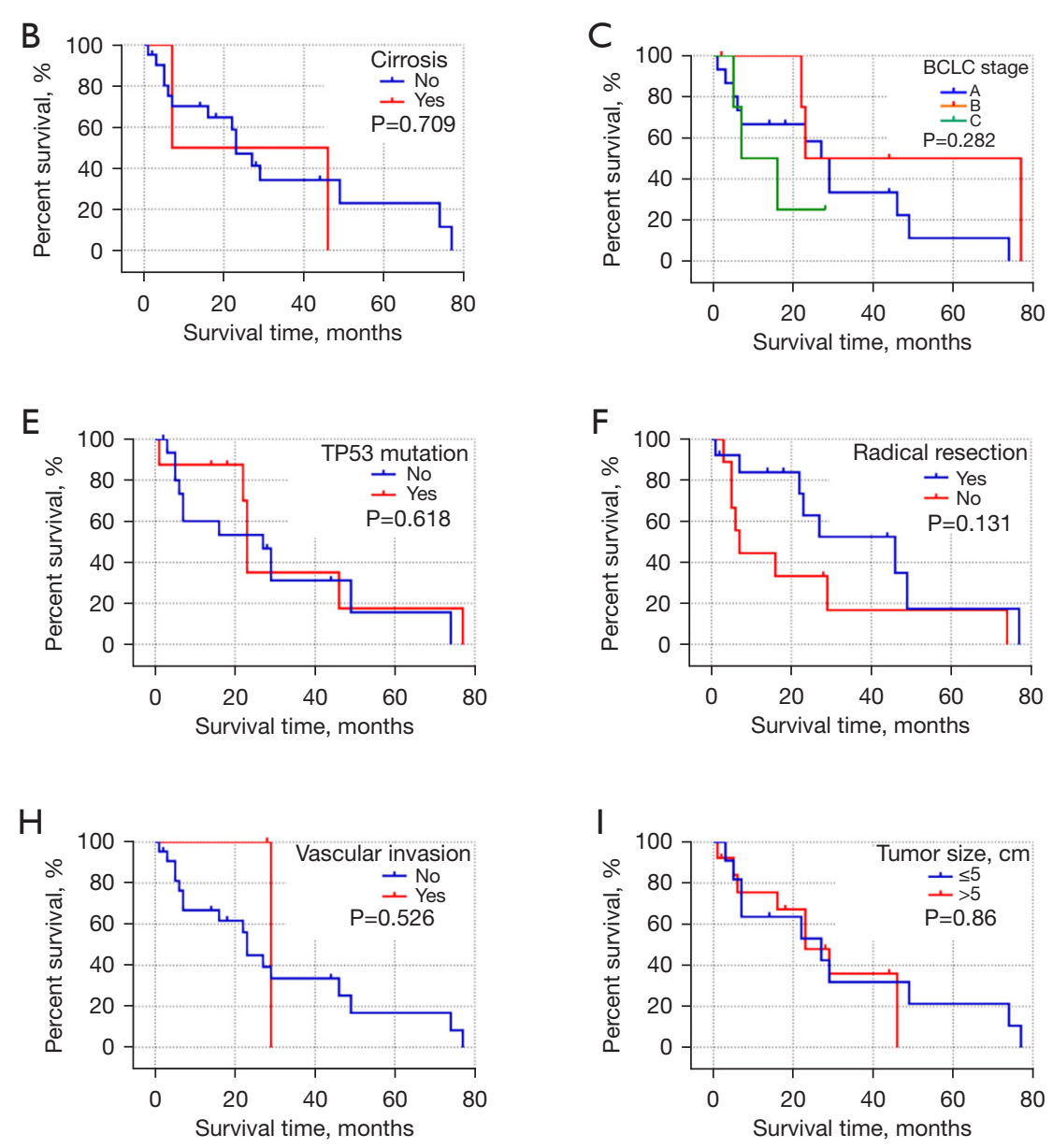

Figure 1 Survival curve of clinical pathology data of primary tumor and long-term DFS time. (A) Association of Child-Pugh score with DFS time of HCC patients; (B) association of cirrhosis with disease-free survival time of HCC patients; (C) association of BCLC staging with DFS time of HCC patients; (D) association of tumor differentiation with DFS time of HCC patients; (E) association of TP53 mutation and DFS time of HCC patients; (F) association of radical resection with DFS of HCC patients; (G) association of AFP level with DFS time of HCC patients; $(\mathrm{H})$ association of Vascular invasion with long-term DFS time of HCC patients; (I) association of tumor size with DFS time of HCC patients; $(\mathrm{J})$ association of tumor number with DFS time of HCC patients. DFS, disease-free survival; BCLC, Barcelona Clinic Liver Cancer; HCC, hepatocellular carcinoma; AFP, alpha fetoprotein. 

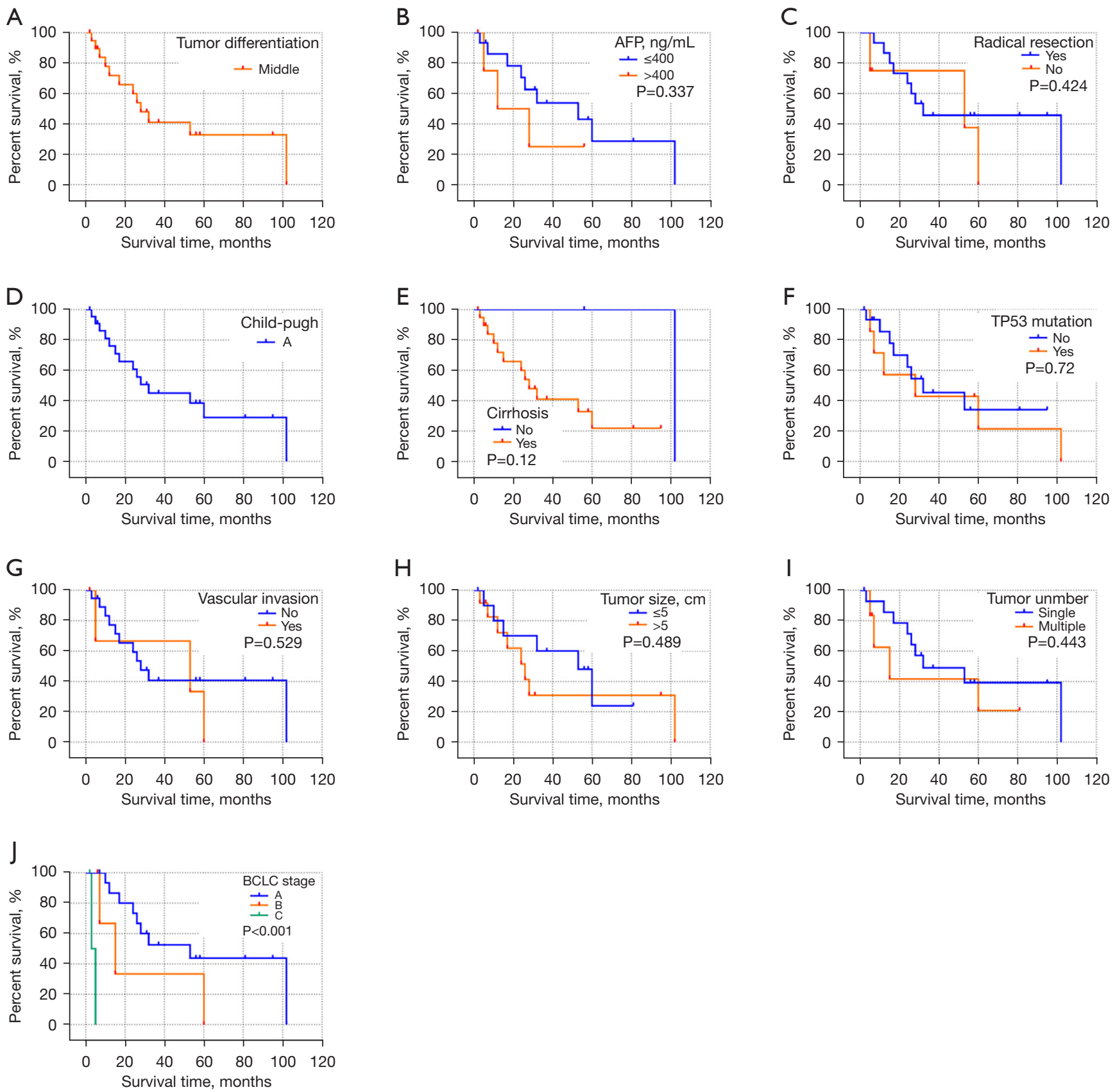

Figure 2 Survival curve of clinical pathology data of tumor recurrence and long-term DFS time. (A) Association of tumor differentiation with DFS time of HCC patients; (B) association of AFP level with DFS time of HCC patients; (C) association of radical resection with DFS time of HCC patients; (D) association of Child-Pugh score with DFS time of HCC patients; (E) association of cirrhosis and DFS time of HCC patients; (F) association of TP53 mutation with DFS of HCC patients; (G) association of vascular invasion with DFS time of HCC patients; $(\mathrm{H})$ association of tumor size with long-term DFS time of HCC patients; (I) association of tumor number with DFS time of HCC patients; (J) association of BCLC staging with DFS time of HCC patients. DFS, disease-free survival; HCC, hepatocellular carcinoma; AFP, alpha fetoprotein; BCLC, Barcelona Clinic Liver Cancer. 

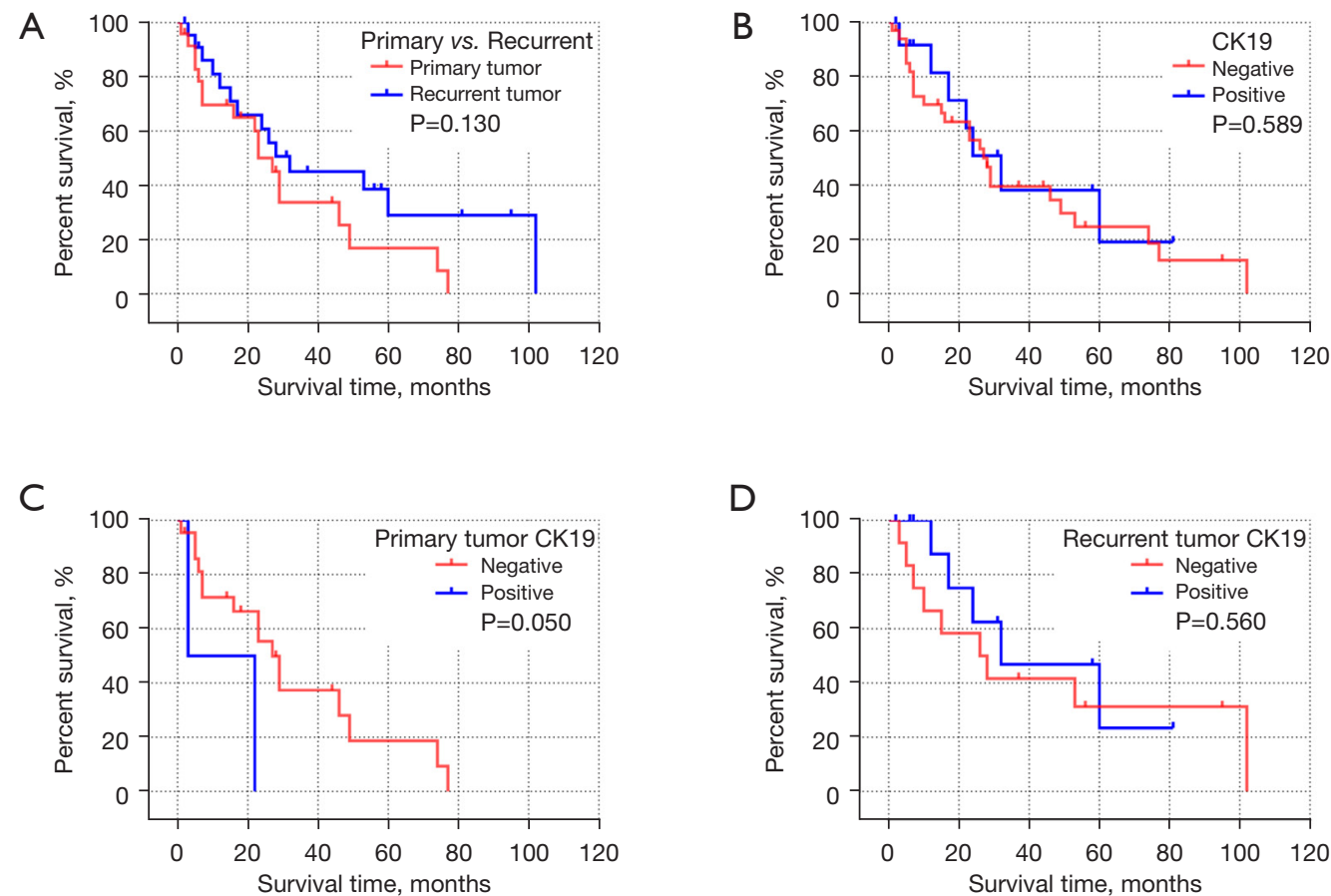

Figure 3 Survival curve of clinical pathological data and tumor-free survival time. (A) Comparison of tumor-free survival time of primary tumors and recurrent tumors in patients with HCC; (B) comparison of tumor-free survival time of patients with positive expression of CK19 and negative expression of HCC; (C) absence of positive CK19 expression and negative expression of HCC patients comparison of tumor survival time; (D) comparison of tumor-free survival time of patients with positive CK19 expression and negative expression of HCC. CK19, cytokeratin 19; HCC, hepatocellular carcinoma.

The GO and KEGG enrichment analyses suggested that the differentially expressed genes were mainly related to negative regulation of cell growth, cell senescence, and the occurrence of HCC related to hepatitis B, but no clear tumor-related gene functions and regulatory pathways were found (Figure 6). Through the combined analysis of differential lncRNA-miRNA, lncRNA-mRNA, and miRNA-mRNA targeting relationships, the relationship pairs with differences among the 3 were extracted for each differential combination, and there were more than 6,000 differential lncRNA-miRNA-mRNA relationship pairs (Figure 7).

\section{Discussion}

Primary HCC is one of the most common malignant tumors in China. It is a malignant tumor with a high fatality rate and poses a serious threat to the health of Chinese people. Studies have shown that the Guangxi Zhuang Autonomous Region has a high incidence of PLC (13). The main pathogenic factors of HCC in Guangxi are aflatoxin exposure and HBV infection. Radical surgical resection of liver tumors is still the main treatment method for PLC at the present stage. Previous studies have shown that the 5 -year survival rate of HCC is about $10 \%$, with poor longterm efficacy (14). Even for early liver cancer, the 5-year survival rate of patients undergoing surgical treatment is only $50-70 \%$ (15), thus reducing the recurrence rate after $\mathrm{HCC}$ resection. Improving postoperative survival is a challenge for surgeons.

In a normal liver, biliary epithelial cells express CK7 and CK19 as well as CK8 and CK18 $(16,17)$. The CK19 gene is a marker of biliary epithelial cells and HPC and can be expressed in some HCCs. Some researchers analyzed 60 cases of focal mass, adenoma, early and late HCC, and found that $C K 19$ was expressed in about $50 \%$ of persistent nodules and all HCC, and in 14\% of cirrhotic remodeled nodules (18). In this study, CK19 was only expressed in cancer tissues regardless of primary or recurrent tumors, and no expression of $C K 19$ was detected in adjacent tissues. The CK19 protein 

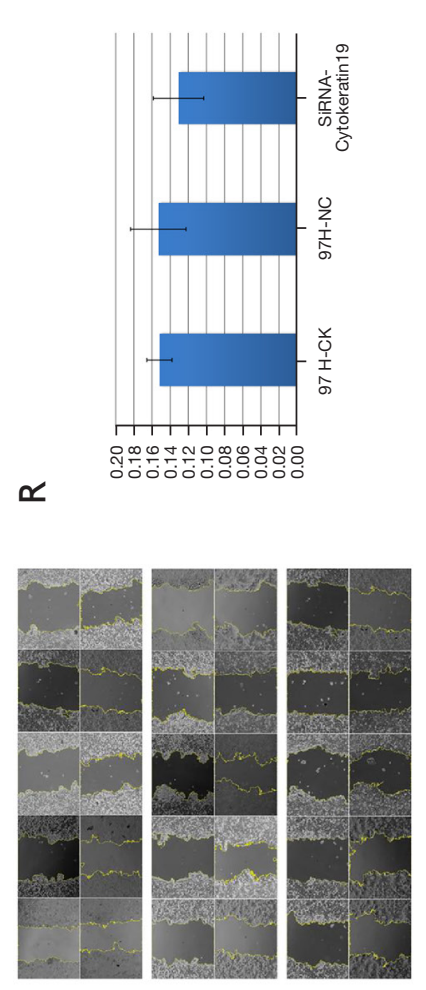

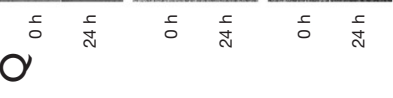

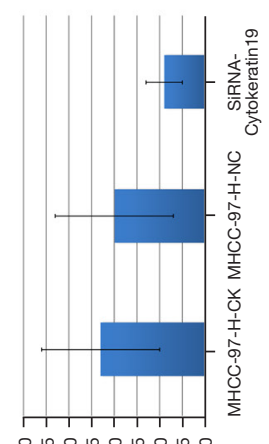

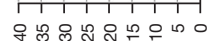

○

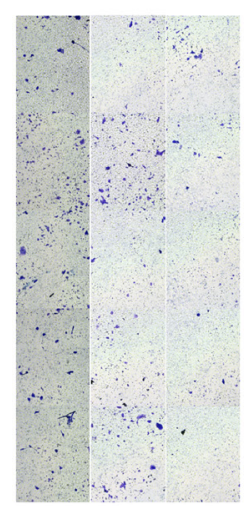

$\varangle \quad \infty \quad U$

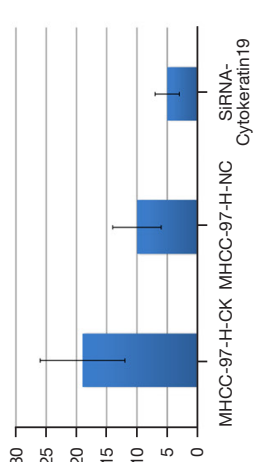

工

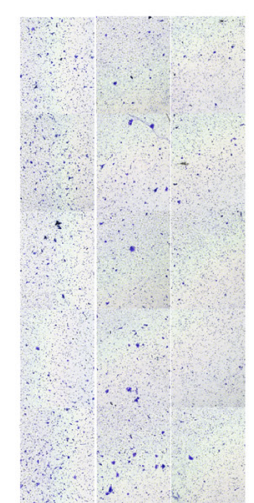

Ш ᄂ

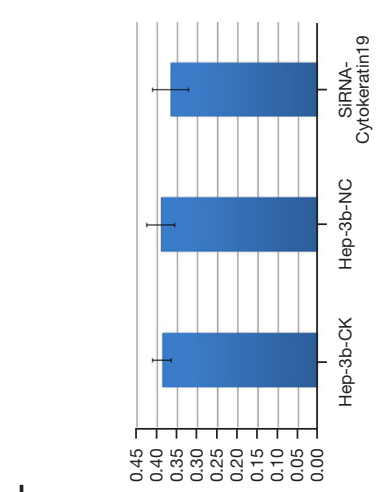

$\vdash$
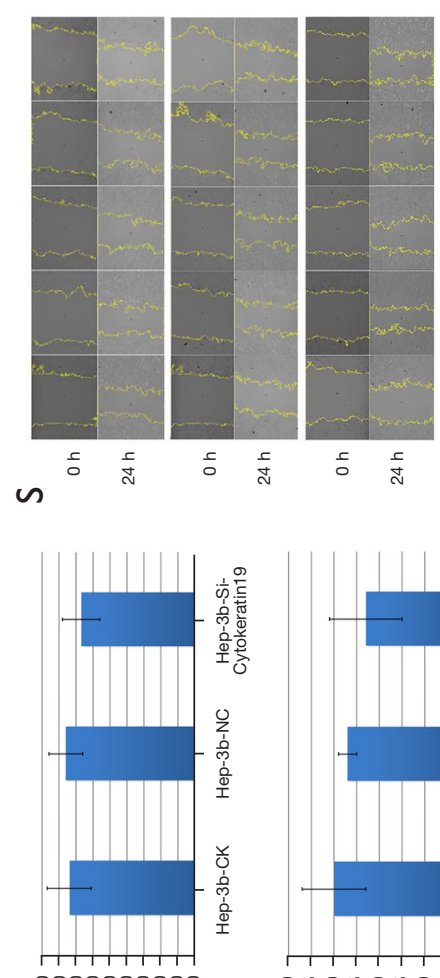

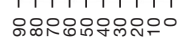
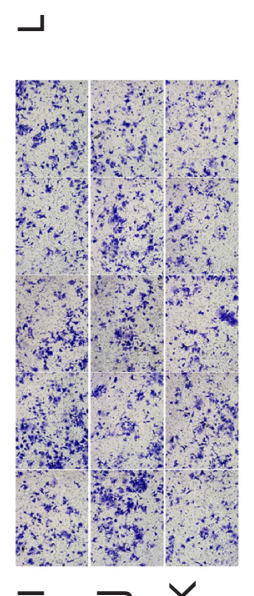

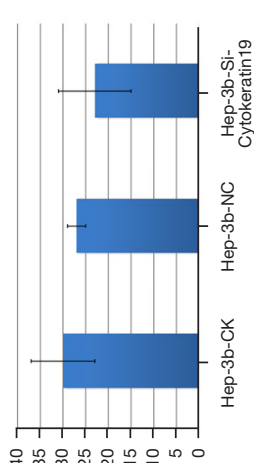

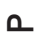

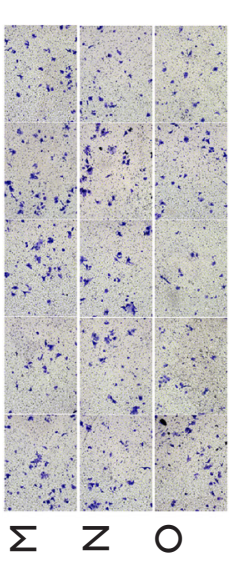

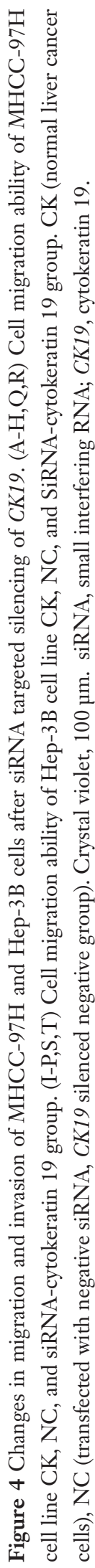



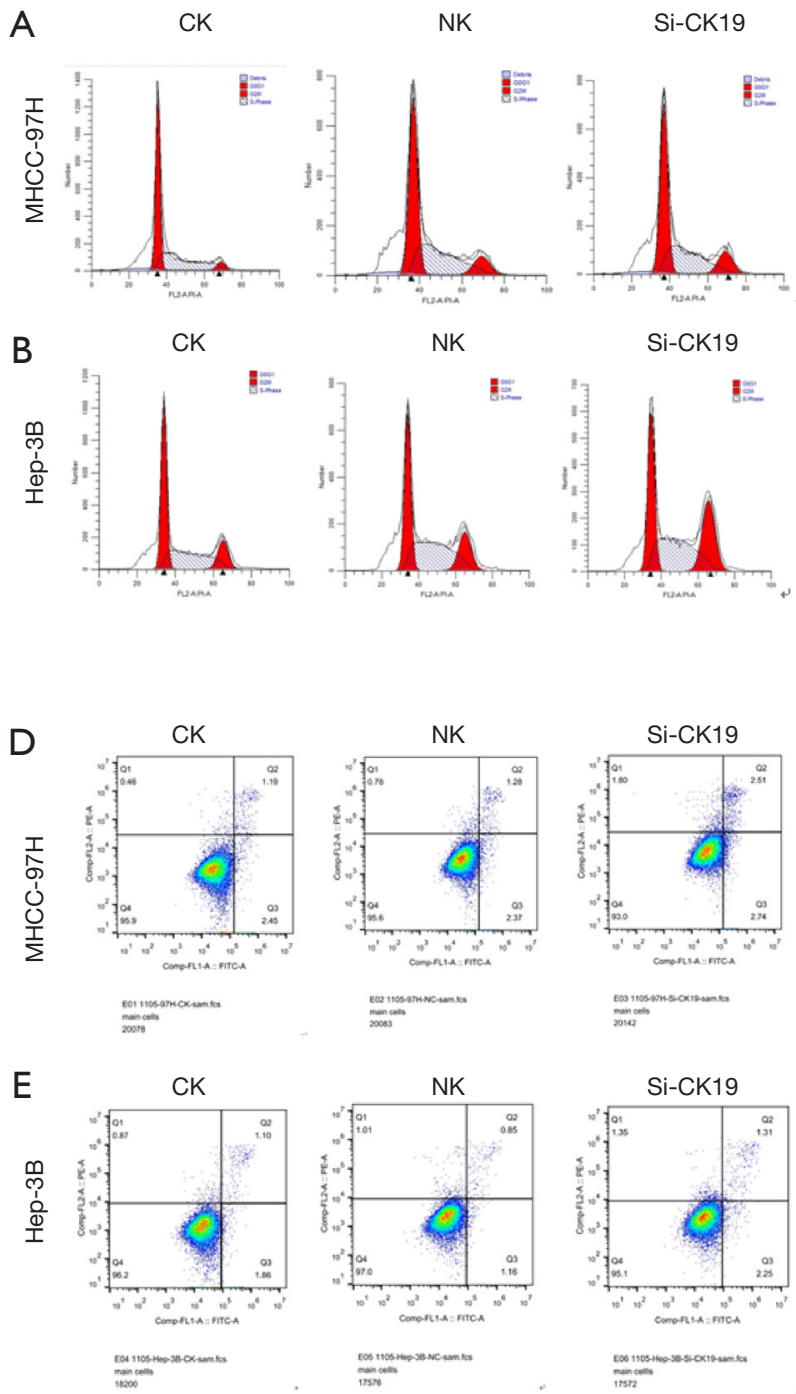

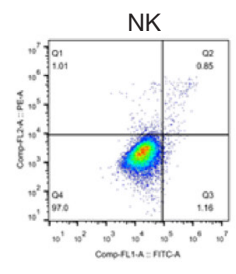

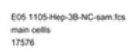

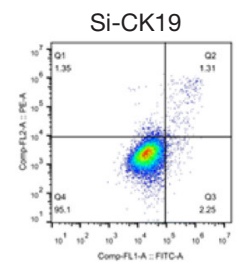

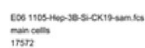

C

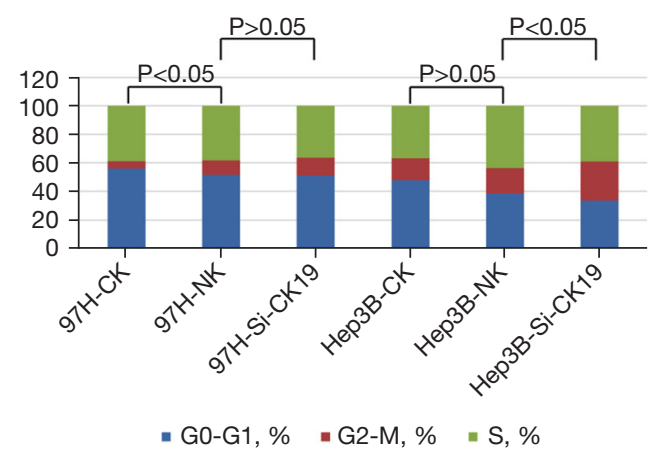

$\mathrm{F}$

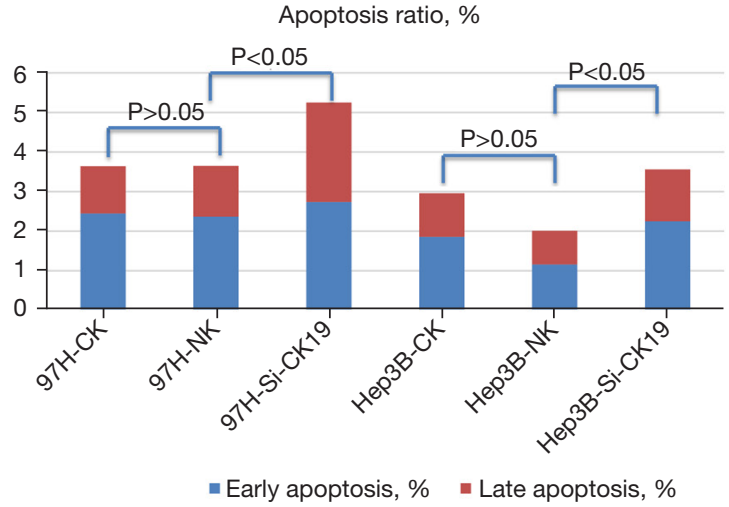

Figure 5 Changes of MHCC-97H and Hep-3B cell cycle and apoptosis after siRNA targeted silencing of CK19. (A-C) Changes in cell cycle of liver cancer cell lines MHCC-97H and Hep-3B after siRNA targeting silencing CK19 gene. (D-F) Effect of siRNA targeting silencing CK19 gene on apoptosis of hepatoma cell line MHCC-97H and Hep-3B. siRNA, small interfering RNA; CK19, cytokeratin 19.

expression was detected in only 2 cases $(8.33 \%)$ of the 24 HCC primary tumor tissues, lower than the positive rate of CK19 IHC detection in HCC tissues reported in previous studies $(9,19)$. In contrast, 11 cases $(45.83 \%)$ of recurrent HCC tumors detected positive for CK19 protein, which was significantly higher than that of the primary tumor, and the differentiation degree of recurrent HCC tumors was significantly different from that of the primary tumor, and the differentiation degrees of recurrent HCC tumors were all moderate. These results suggested that the differentiation degree of recurrent HCC tumors would change, and the positive rate of $C K 19$ expression would be higher. However, not all recurrent HCC tumors expressed CK19, and in this study, a patient with positive expression of primary HCC tumors showed negative CK19 expression of the recurrent tumor, which may be related to tumor heterogeneity. The HCC is a heterogeneous disease of different clinical subgroups, and the main source of tumor heterogeneity may be the origin of cell types. In the liver, such cell types include hepatocytes and adult progenitor cells (19). In addition, the evolution of HCC tumors may also be responsible for this phenomenon $(20,21)$. 
A

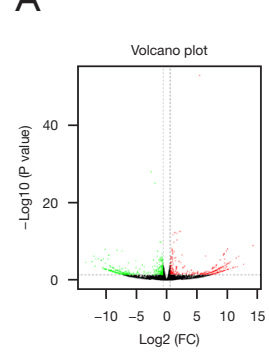

D

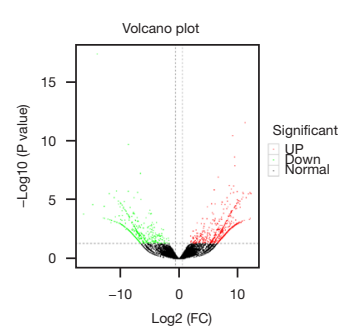

G

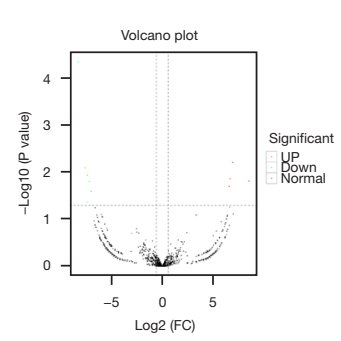

J

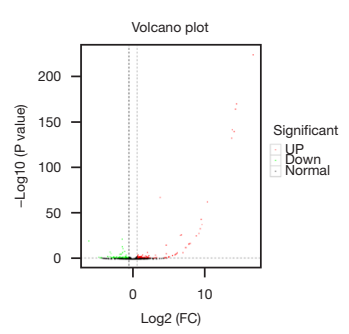

B

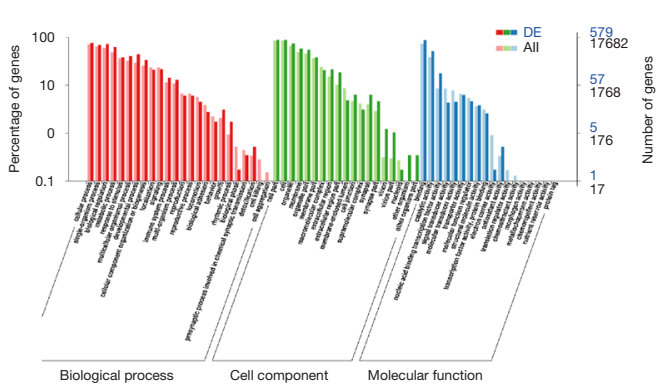

E

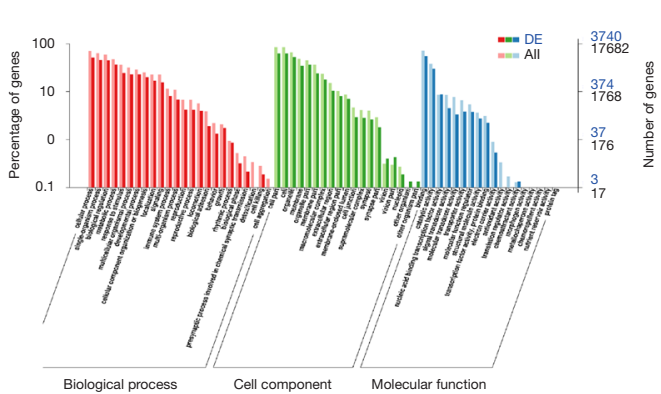

$\mathrm{H}$

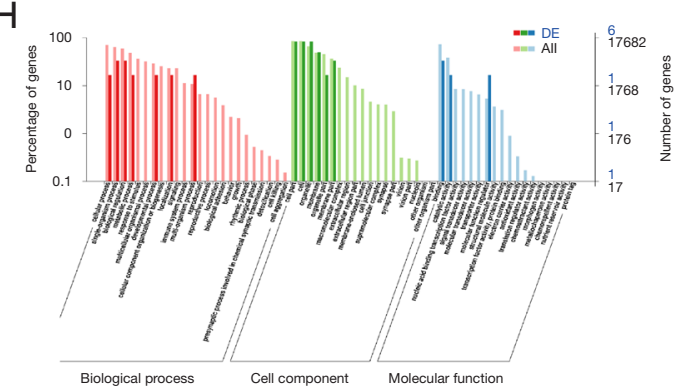

$\mathrm{K}$

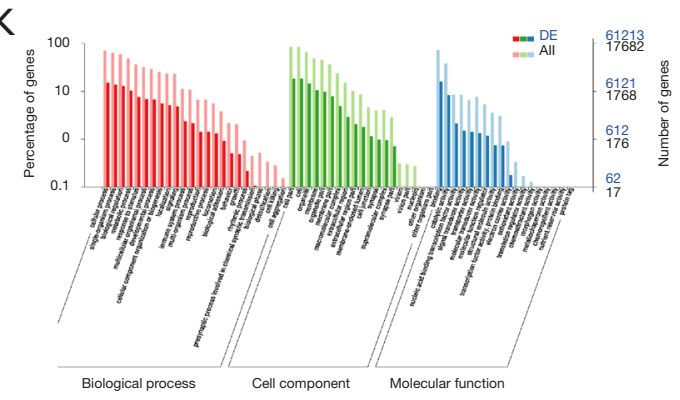

I
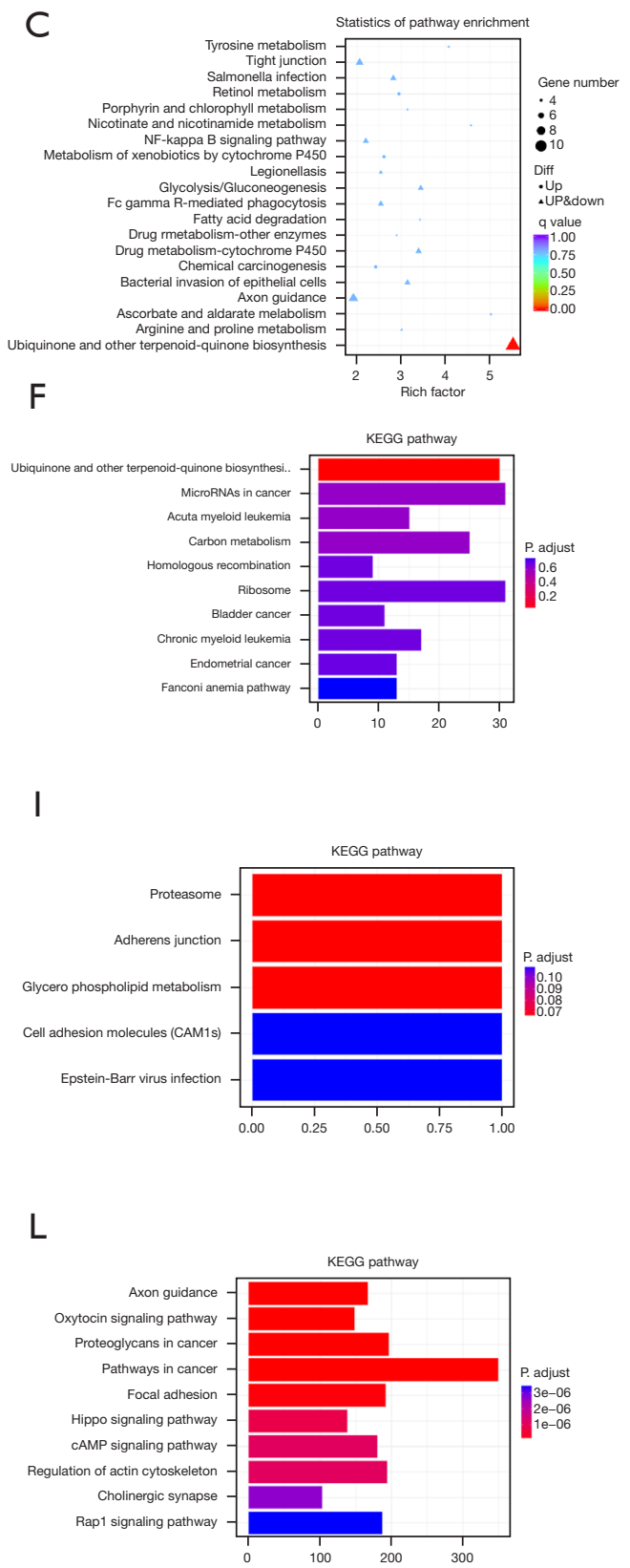

Figure 6 Full transcriptome analysis of Hep-3B cells after siRNA targeted silencing of CK19. (A-C) mRNA differentially expressed genes, GO and KEGG analysis. (D-F) Differentially expressed lncRNA genes, GO and KEGG analysis. (G-I) CircRNA differentially expressed genes, GO and KEGG analysis. (J-L) Differentially expressed miRNA genes, GO and KEGG were analyzed. siRNA, small interfering RNA; CK19, cytokeratin 19; mRNA, messenger RNA; GO, Gene Ontology; KEGG, Kyoto Encyclopedia of Genes and Genomes.

Studies have shown that the HCC subtypes expressing CK19 are significantly associated with tumor size, low differentiation, microvascular invasion, metastasis, and recurrence, with poor prognosis $(9,10,19)$. In this study, we found that the tumor-free survival time (median recurrence time: 3 months) of patients with positive CK19 expression in HCC primary tumors was significantly lower than that of patients with negative $C K 19$ expression (median recurrence time: 27 months), which was similar to the results of other studies. Among recurrent HCC tumors, there was no 


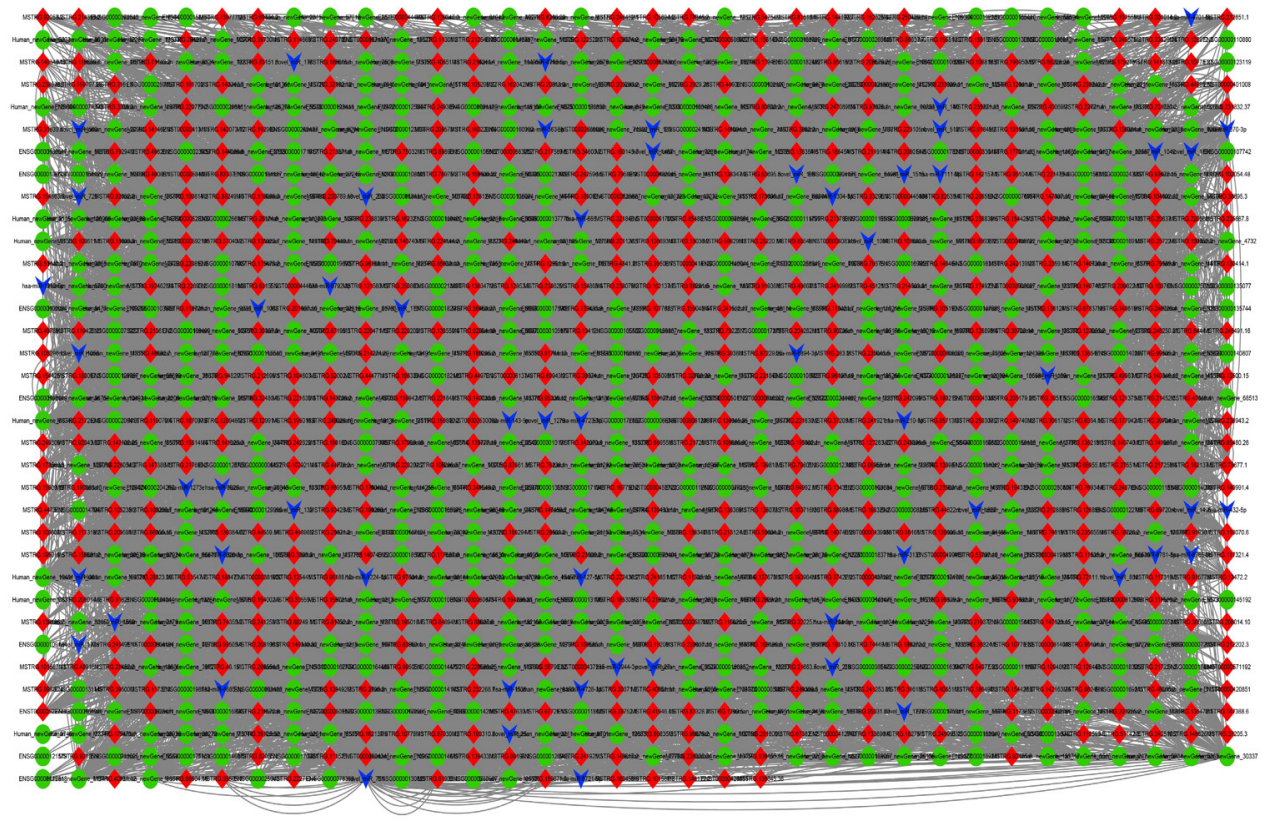

Figure 7 Differential lncRNA-miRNA-mRNA relationship pairs. lncRNA, long non-coding RNA; miRNA, micro RNA; mRNA, messenger RNA.

statistically significant difference in the tumor-free survival time of patients with positive CK19 expression (median recurrence time: 32 months) and patients with negative CK19 expression (median recurrence time: 26 months), which may be due to the small number of patients enrolled and only 2 patients with positive $C K 19$ expression in the primary tumors. Our result may not be an adequate reflection of the actual situation, so we need to further expand the sample size for further study in the future.

In this study, horizontal migration, vertical migration, and invasion ability of MHCC-97H cells were significantly decreased after siRNA silencing of the CK19 gene, suggesting that CK19 (+) HCC cells had stronger invasion ability and less favorable prognosis than CK19 (-) HCC cells, which was consistent with the results of Takano et al. (22). The possible mechanism is as follows: after silencing CK19 by siRNA transfection, E-cadherin gene expression was upregulated, and angiogenesis-related molecules such as angiostatin-1 (VASH1), fibroblast growth factor 1 (FGFR1), and angiostatin-2 (VASH2) were downregulated by significantly inhibiting the invasion ability of cells. The possible mechanism for the worse prognosis of CK19-positive HCC also includes the activation of the epidermal cell growth factor (EGF)-epidermal growth factor receptor (EGFR) signaling pathway, which enables HCC cells to express CK19 after EGF stimulation and enhances the ability of both reproduction and invasion of HCC cells (23). In MHCC-97H and Hep-3B, compared with other groups, the percentage of cell content in the G2 phase increased, and the percentage of cell apoptosis in MHCC-97H and Hep-3B also increased significantly. These results suggest that $C K 19$ silencing can inhibit HCC proliferation by inducing cell cycle stagnation in the G2-M phase, possibly because $C K 19$ silencing inhibits cell growth by inducing apoptosis or upregulating P16 and P27, leading to cell senescence (22).

In this study, dysregulation of miRNAs and lncRNAs was widely found in HCC, which is closely related to tumorigenesis, diagnosis, and prognosis. By using multilevel comprehensive gene expression analysis (GEO) and bioinformatics calculation methods, 9 groups of HCC-related RNAs were analyzed and a regulatory or co-expression network of lncRNA-miRNA-mRNA was constructed among differentially expressed mRNAs, miRNAs, and lncRNAs. The regulatory roles of $10 \mathrm{lncRNAs}$ and miRNAs were verified (14).

In this study, GO and KEGG enrichment analysis of 
differentially expressed mRNA and lncRNA indicated that the differentially expressed mRNA of CK19 positive HCC was mainly related to the negative regulation of cell growth and gene function change of cell aging, which may be a potential factor affecting the higher malignant biological behavior of CK19 positive HCC. Some researchers have found that genes related to the mitotic cell cycle process, cell division, and mitotic cell cycle are key genes and potential molecular mechanisms for the occurrence and development of HCC (24). The differential lncRNA-miRNA-mRNA relationship based on competing endogenous RNA (ceRNA) network has a complex mutual regulation relationship, suggesting that after siRNA silencing of $C K 19$, the mRNA expression level of HCC cells is affected by both lncRNA and miRNA. The lncRNA and miRNA interact with each other. A single lncRNA or miRNA can affect multiple target genes, and the expression level of a single mRNA is jointly regulated by multiple upstream genes. Through the above interaction and regulation, a complex lncRNAmiRNA-mRNA regulatory network is formed. It also plays a physiological role in the occurrence, development, and higher malignant biological progression of CK19 positive HCC.

Our research can open up a new path for the targeted therapy of liver cancer. Although it is still in the initial stage, with the in-depth research and the breakthrough of various bottlenecks, it is possible to significantly improve the therapeutic effect of liver cancer. This study had some limitations. On the one hand, the sample size of the included study population was relatively small, and it was a single-center sample. On the other hand, this study was a retrospective case-control study and lacked the structure of a prospective randomized controlled trial, which may have affected the quality of the study. Finally, the differentially expressed sites of CK19 positive HCC screened from sequencing data need further functional verification.

\section{Conclusions}

The positive rate of $C K 19$ expression in recurrent HCC was higher among $\mathrm{HBV}$-associated recurrent $\mathrm{HCC}$ in Guangxi. The HCC patients with positive CK19 expression in primary tumors had a shorter tumor-free survival time, but this phenomenon was not observed in recurrent tumors. After targeted silencing of the CK19 gene in $\mathrm{MHCC}-97 \mathrm{H}$ and Hep-3B, the percentage of cells in the G2 phase and the percentage of cell apoptosis increased, and the cell cycle stagnated in the G2-M phase. Moreover, the proliferation of HCC cells was inhibited, apoptosis was promoted, and the migration and invasion of HCC cells were weakened. Changes in the function of the cell cycle regulating genes, drug, and carcinogenic metabolism-related pathways may be factors affecting the biological behavior of $C K 19$ positive HCC. These results provide evidence for finding the specific mechanism, pathway, and biological process involved affecting CK19 gene expression in $\mathrm{HCC}$.

\section{Acknowledgments}

Funding: This study was supported by the National Natural Science Foundation of China (Nos. NSFC81072321, NSFC81560535, NSFC81802874); New Century Excellent Talents Program of Ministry of Education in 2009, Guangxi Scientific Research and Technology Development Project (No. Guikebao 1104003A-7); Key Scientific Research Project of Guangxi Medical And Health (No. 201018); Young Science Foundation of Guangxi Natural Science Foundation (No. 2018GXNSFBA138013); Guangxi Natural Science Foundation (No. 2018GXNSFAA050119); Basic Ability Improvement Project of Young and Middleaged Teachers in Guangxi Universities (No. 2018KY0110) and Guangxi Key Research and Development Program (No. GKEAB18221019).

\section{Footnote}

Reporting Checklist: The authors have completed the MDAR reporting checklist. Available at https://dx.doi. org/10.21037/atm-21-6020

Data Sharing Statement: Available at https://dx.doi. org/10.21037/atm-21-6020

Conflicts of Interest: All authors have completed the ICMJE uniform disclosure form (available at https://dx.doi. org/10.21037/atm-21-6020). The authors have no conflicts of interest to declare.

Ethical Statement: The authors are accountable for all aspects of the work in ensuring that questions related to the accuracy or integrity of any part of the work are appropriately investigated and resolved. The study was conducted in accordance with the Declaration of Helsinki (as 


\section{Page 18 of 19}

revised in 2013), and approved by the Ethics Committee of The First Affiliated Hospital of Guangxi Medical University (No. 2015-KY-072). The patients were fully informed about the nature of this experiment and their informed consent was provided.

Open Access Statement: This is an Open Access article distributed in accordance with the Creative Commons Attribution-NonCommercial-NoDerivs 4.0 International License (CC BY-NC-ND 4.0), which permits the noncommercial replication and distribution of the article with the strict proviso that no changes or edits are made and the original work is properly cited (including links to both the formal publication through the relevant DOI and the license). See: https://creativecommons.org/licenses/by-nc-nd/4.0/.

\section{References}

1. Forner A, Reig M, Bruix J. Hepatocellular carcinoma. Lancet 2018;391:1301-14.

2. Siegel RL, Miller KD, Jemal A. Cancer statistics, 2020. CA Cancer J Clin 2020;70:7-30.

3. Qin W, Han C, Mai R, et al. Establishment of a prognostic model for predicting short-term disease-free survival in cases of hepatitis B-related hepatocellular carcinoma with the TP53 249Ser mutation in southern China. Transl Cancer Res 2020;9:4517-33.

4. Yeh FS, Mo CC, Yen RC. Risk factors for hepatocellular carcinoma in Guangxi, People's Republic of China. Natl Cancer Inst Monogr 1985;69:47-8.

5. Yeh FS, Yu MC, Mo CC, et al. Hepatitis B virus, aflatoxins, and hepatocellular carcinoma in southern Guangxi, China. Cancer Res 1989;49:2506-9.

6. Peng T, Li LQ, Peng MH, et al. Evaluation of oxidative stress in a group of adolescents exposed to a high level of aflatoxin B1--a multi-center and multi-biomarker study. Carcinogenesis 2007;28:2347-54.

7. Liu ZM, Li LQ, Peng MH, et al. Hepatitis B virus infection contributes to oxidative stress in a population exposed to aflatoxin B1 and high-risk for hepatocellular carcinoma. Cancer Lett 2008;263:212-22.

8. Woo HG, Lee JH, Yoon JH, et al. Identification of a cholangiocarcinoma-like gene expression trait in hepatocellular carcinoma. Cancer Res 2010;70:3034-41.

9. Govaere O, Komuta M, Berkers J, et al. Keratin 19: a key role player in the invasion of human hepatocellular carcinomas. Gut 2014;63:674-85.

10. Lee JS, Heo J, Libbrecht L, et al. A novel prognostic

\section{Su et al. Study on the regulatory mechanism of CK19 in HCC}

subtype of human hepatocellular carcinoma derived from hepatic progenitor cells. Nat Med 2006;12:410-6.

11. Han C. Feature screening and functional identification of polymorphisms in whole exons affecting codon 249 mutation of TP53 gene of AFB1/HBV double-exposed primary hepatocellular carcinoma subtype in Guangxi. Guangxi Medical University. 2017.

12. Zhu G Z. Study on the molecular mechanism of regulating the expression of CK7 and CK19 in hepatitis B associated primary hepatocellular carcinoma in Guangxi. Guangxi Medical University; 2018.

13. Zhou M, Wang H, Zhu J, et al. Cause-specific mortality for 240 causes in China during 1990-2013: a systematic subnational analysis for the Global Burden of Disease Study 2013. Lancet 2016;387:251-72.

14. Zeng H, Zheng R, Guo Y, et al. Cancer survival in China, 2003-2005: a population-based study. Int J Cancer 2015;136:1921-30.

15. European Association for the Study of the Liver. Electronic address: easloffice@easloffice.eu; European Association for the Study of the Liver. EASL Clinical Practice Guidelines: Management of hepatocellular carcinoma. J Hepatol 2018;69:182-236.

16. Moll R, Franke WW, Schiller DL, et al. The catalog of human cytokeratins: patterns of expression in normal epithelia, tumors and cultured cells. Cell 1982;31:11-24.

17. Strnad P, Stumptner C, Zatloukal K, et al. Intermediate filament cytoskeleton of the liver in health and disease. Histochem Cell Biol 2008;129:735-49.

18. Andersen JB, Loi R, Perra A, et al. Progenitor-derived hepatocellular carcinoma model in the rat. Hepatology 2010;51:1401-9.

19. Durnez A, Verslype C, Nevens F, et al. The clinicopathological and prognostic relevance of cytokeratin 7 and 19 expression in hepatocellular carcinoma. A possible progenitor cell origin. Histopathology 2006;49:138-51.

20. Poon TC, Wong N, Lai PB, et al. A tumor progression model for hepatocellular carcinoma: bioinformatic analysis of genomic data. Gastroenterology 2006;131:1262-70.

21. Miao R, Luo H, Zhou H, et al. Identification of prognostic biomarkers in hepatitis B virus-related hepatocellular carcinoma and stratification by integrative multi-omics analysis. J Hepatol 2014;61:840-9.

22. Takano M, Shimada K, Fujii T, et al. Keratin 19 as a key molecule in progression of human hepatocellular carcinomas through invasion and angiogenesis. BMC Cancer 2016;16:903. 
23. Yoneda N, Sato Y, Kitao A, et al. Epidermal growth factor induces cytokeratin 19 expression accompanied by increased growth abilities in human hepatocellular carcinoma. Lab Invest 2011;91:262-72.

24. Zhou L, Du Y, Kong L, et al. Identification of molecular

Cite this article as: Su H, Han C, He Y, Liang T, Mo S, Yang C, Liao X, Zhu G, Ye X, Peng T. Molecular mechanism of CK19 involved in the regulation of postoperative recurrence of $\mathrm{HBV}$ associated primary hepatocellular carcinoma in Guangxi. Ann Transl Med 2021;9(24):1780. doi: 10.21037/atm-21-6020 target genes and key pathways in hepatocellular carcinoma by bioinformatics analysis. Onco Targets Ther 2018;11:1861-9.

(English Language Editor: J. Jones) 


\section{Supplementary}

Table S1 Basic clinical information of 24 HCC patients

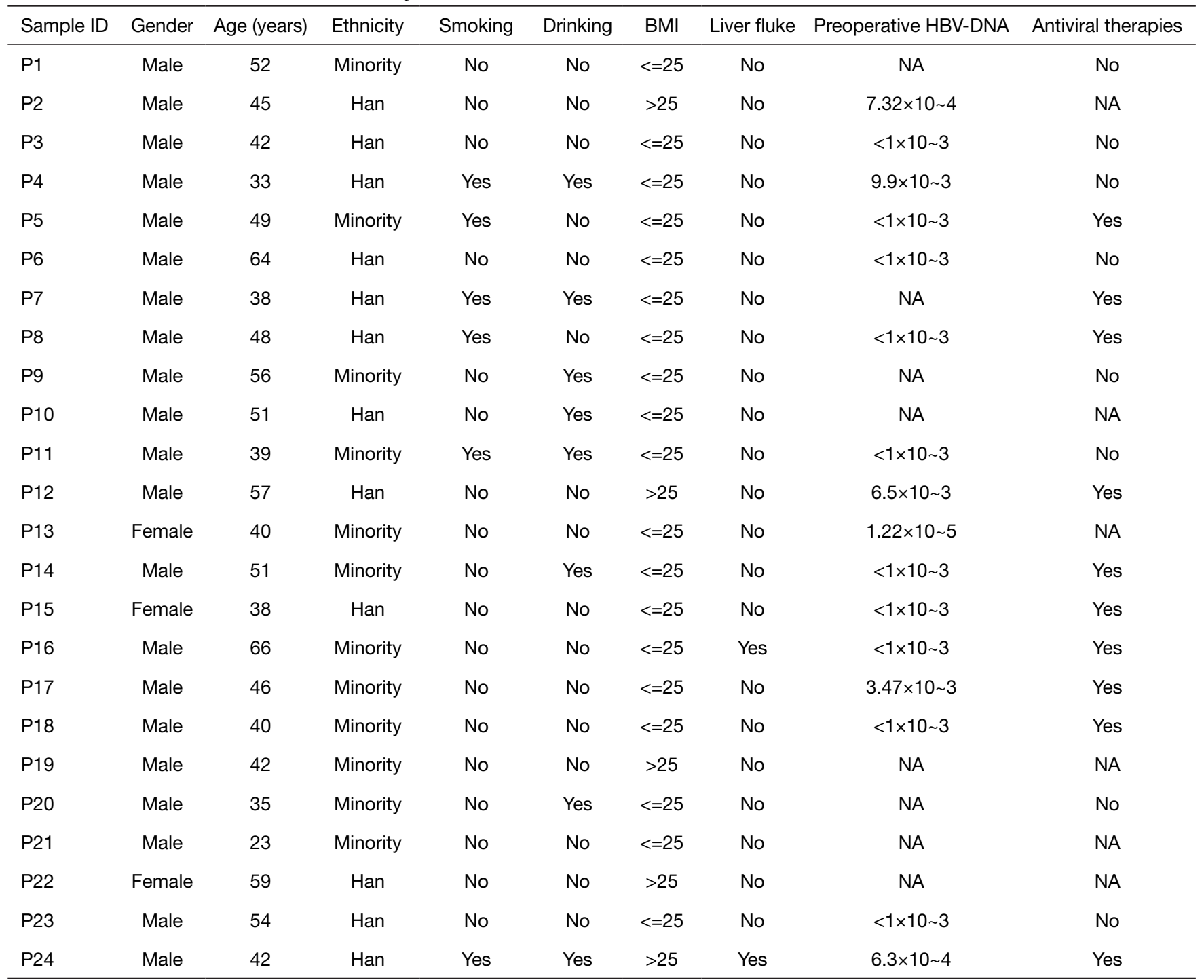

$\mathrm{NA}$, not available; HCC, hepatocellular carcinoma; BMI, body mass index; HBV, hepatitis B virus. 


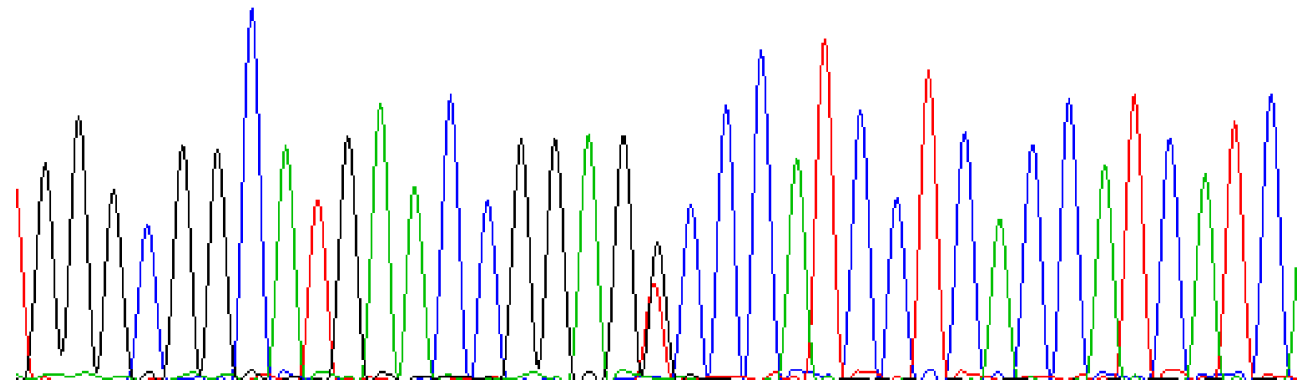

Figure S1 Gene sequencing of TP53 G249T patients.

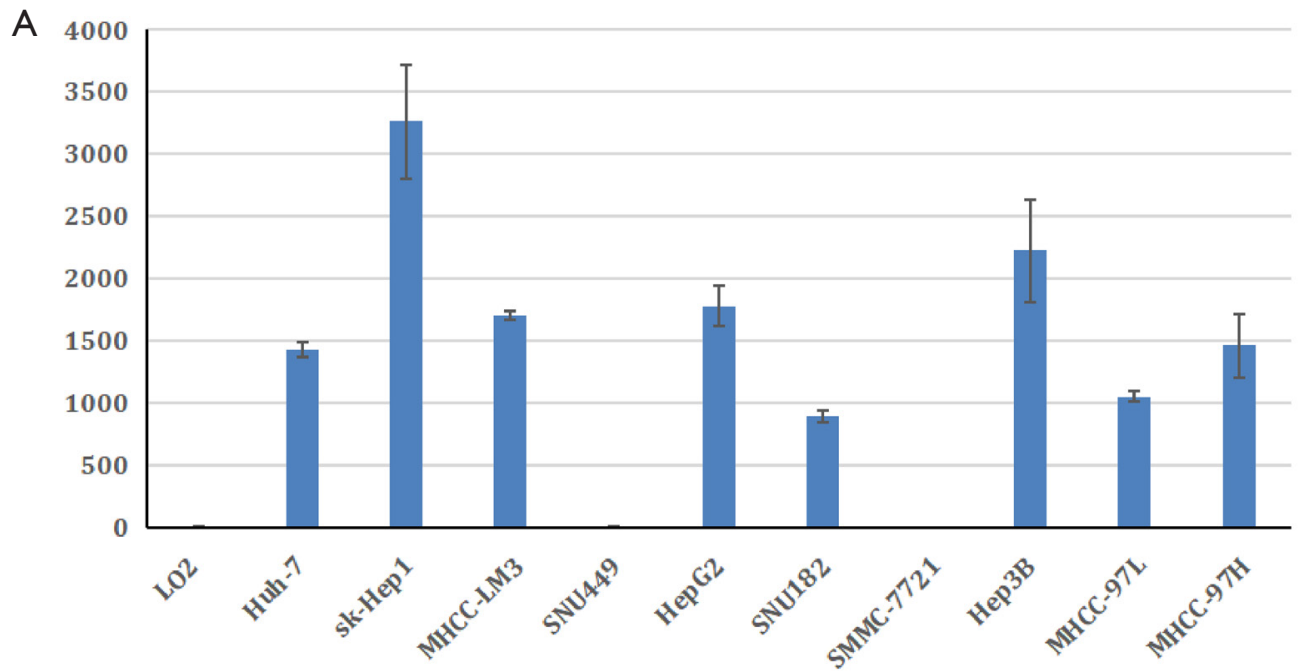

B

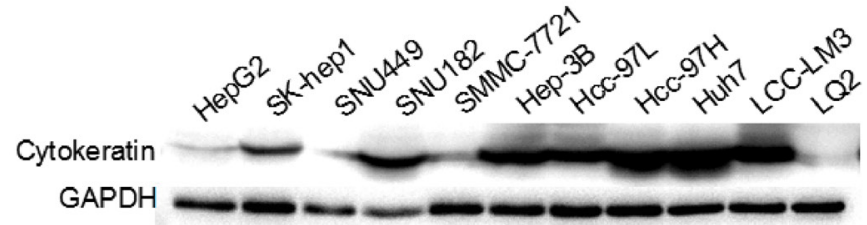

Figure S2 The relative expression level of CK19 relative to normal liver cells (LO2) in each cell line. (A) Relative expression levels of CK19 gene relative to normal hepatocytes (LO2) in each cell line sample. (B) Results of CK19 protein expression in each liver cancer cell line. 
A

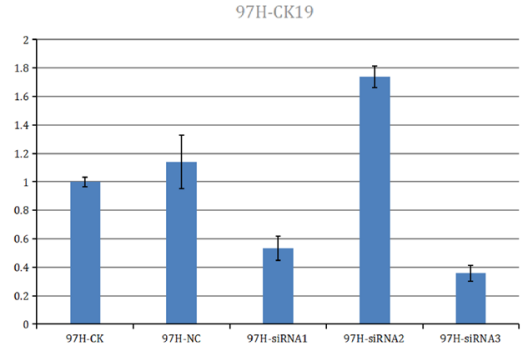

C

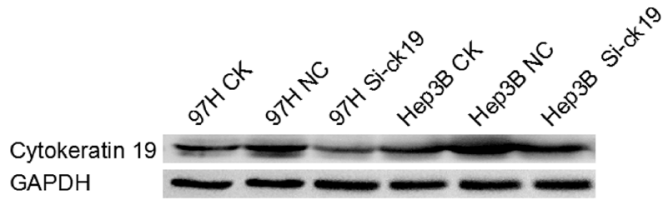

B

Hep3B-CK19

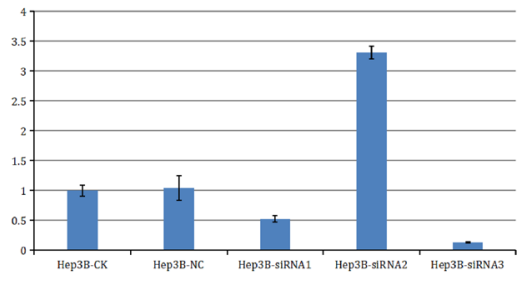

D

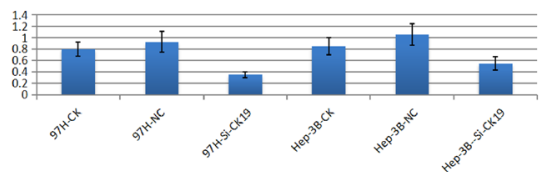

Figure S3 Expression level of CK19 gene in MHCC-97H and Hep-3B cells. (A) Expression level of CK19 gene in each sample in MHCC97H cells. (B) Expression level of CK19 gene in Hep3B cells in each sample. (C) Protein expression results of CK19 in hepatocarcinoma cell lines MHCC-97H and Hep-3B after siRNA silencing. (D) Relative protein expression levels of CK19 in hepatocellular carcinoma cell lines MHCC-97H and Hep-3B after siRNA silencing. siRNA, small interfering RNA. 